\title{
CONTROLE QUÍMICO DE PERCEVEJOS DA SOJA NO VALE DO SÃO PATRÍCIO
}

\author{
CHEMICAL CONTROL OF SOY PERCEPTIONS IN THE SÃO PATRÍCIO VALLEY
}

\author{
Romário Soares de Jesus ${ }^{1}$, Elieser Silva Gomes ${ }^{1}$, Daniel Ferreira Caixeta ${ }^{2}$
}

${ }^{1}$ Engenheiro Agrônomo, Faculdade Evangélica de Goianésia;

${ }^{2}$ Professor da Faculdade Evangélica de Goianésia.

\section{Info}

Recebido: 07/2020

Publicado: $12 / 2020$

ISSN: 2595-6906

DOI: $10.37951 / 2595-6906.2020 v 4 \mathrm{i} 2.6364$

Palavras-Chave

MIP, doses, adjuvantes

Keywords:

MIP, doses, adjuvants

\section{Resumo}

Há uma discussão constante entre os produtos sobre qual produto é mais eficiente no controle dos percevejos da soja. Assim, o objetivo desse trabalho será a avaliar a eficiência dos principais inseticidas utilizados no controle dos percevejos da cultura da soja na Região de Goianésia e Vila Propício-GO, e testar aditivos e adjuvantes que maximizem a eficiência de controle desses produtos. 0 estudo foi conduzido na fazenda Pai José, no município de Vila Propício-GO. 0 delineamento experimental foi o de blocos ao acaso com parcelas subdivididas em esquema fatorial 9x3, com oito inseticidas/dosese um controle, três tratamentos $(\mathrm{NaCl}$, Acquamax $\AA$, e sem aditivo/adjuvante) e quatro repetições. Ao todo, foram testadas 27 cenários distintos. A aplicação foi realizada por meio de pulverizador costal de pesquisa (Herbicat $\AA$ ), com barra de seis pontas (100-02) espaçadas a 0,5m, com faixa aplicada de 3 metros. 0 volume de calda utilizado foi de 150l/ha, com pressão de $0,75 \mathrm{Kgf}$, e velocidade de 4,5 km/h. Os dados foram submetidos à análise de variância utilizando o procedimento GLM, seguido do teste de Tukey para separação das médias. As transformações utilizadas foram para as variáveis numero de percevejos por metro antes, e com 24 e 72 horas após a aplicação. A eficiência de controle foi transformada utilizando o arco-seno +0,5. O Connect ${ }^{\circledR}$ 11/ha (Imidacloprido+Betaciflutrina) reduziu a população dos percevejos de 12,4 pata 1,4 percevejos por metro com 24 horas após a aplicação. Perito® $1 \mathrm{~kg} / \mathrm{ha}$ (Acefato) foi o produto o residual mais alto, apresentando mais de $80 \%$ de eficiência de controle com 72 horas após a instalação do ensaio. Nenhum inseticida manteve a população de percevejos abaixo do Nível de Controle no terceiro dia após a aplicação. Os Neonicotinoides+Piretóides e Organosfosforados foram mais eficientes no controle de percevejos do que os Piretróides. Não há justificativa econômica ou agronômica para a utilização do adjuvante Acquamax® na aplicação de inseticidas. Engeo Pleno® (Tiametoxan+Lambdacialotrina) e o Perito® (Acefato) na menor dose possuem alta eficiência de controle e custo 44-30\% menor. A relação de custo-benefício da adição do sal de cozinha se mostrou extremamente vantajosa, com custo de $\mathrm{R} \$ 0,75 /$ ha e aumento na eficiência de controle superior a $15 \%$. 


\section{INTRODUÇÃO}

Atualmente, o Brasil é considerado o segundo maior produtor de soja do mundo. Segundo dados da Companhia Nacional do Abastecimento (CONAB), foram produzidos mais de 110 milhões de toneladas de soja na safra 2017/18, com crescimento de 3,3\% em área plantada. O crescimento do setor reforça a necessidade de utilizar os inseticidas de forma racional para reduzir os impactos ambientais, e evitar a imposição de barreiras comerciais à exportação de soja e derivados (CORRÊA-FERREIRA et al., 2013).

A cultura da soja é alvo de vários insetospraga que podem ocorrer durante todo o ciclo de cultivo. O controle das principais pragas da soja deve ser feito com base nos princípios do Manejo Integrado de Pragas (MIP), que considera a densidade populacional para a tomada de decisão sobre o controle das pragas (FREITAS, 2011). A adoção do nível de controle mantém a densidade populacional das pragas abaixo do nível de dano econômico, e racionaliza o uso dos recursos disponíveis (TEIXEIRA ET al., 2007).

Diversos produtores têm realizado aplicações calendarizadas na cultura da soja, com mais de seis pulverizações por ciclo de cultivo (BUENO ET al., 2010). O uso abusivo dos inseticidas nos últimos anos tem causado surtos de pragas que não eram importantes, como a mosca-branca e as lagartas do gênero Spodoptera (EMBRAPA SOJA, 2014).

Já existem estudos que detectaram taxas de resistência elevadas em populações do percevejo marrom Euchistus heros (Fabricius). Os percevejos causam diversos prejuízos na cultura da soja, como a má formação dos grãos e vagens, grãos chochos, enrugados e amadurecimento desuniforme da lavoura (EMBRAPA SOJA, 2014).

A procura por novas estratégias no controle dos percevejos da soja está cada vez maior, uma vez que o mercado de defensivos agrícolas dispõe de pouquíssimas moléculas (AGROFIT, 2018).

Diversos inseticidas do grupo dos Organofosforados estão sendo banidos, e os Ciclodienos já foram retirados do mercado a alguns anos. Assim, os grupos químicos mais usados para o controle de percevejos são os Piretróides, Neonicotinóides e Organofosforados (BUENO et al., 2012).

Há uma discussão constante entre os produtos sobre qual produto é mais eficiente no controle dos percevejos da soja. Assim, o objetivo desse trabalho foi avaliar a eficiência dos principais inseticidas utilizados no controle dos percevejos da cultura da soja na Região de Goianésia e Vila Propício-GO, e testar aditivos e adjuvantes que maximizem a eficiência de controle desses produtos.

\section{MATERIAL E MÉTODOS}

\subsection{Detalhes do ensaio}

O estudo foi conduzido na fazenda Pai José, no município de Vila Propício-GO, que tem como proprietário o Sr. Fernando Machado Pedrosa. A propriedade planta cerca de 1100 hectares de soja, a variedade escolhida para realização do experimento foi a 6210 Ipro, com cilco de 110 dias. O delineamento experimental foi o de blocos ao acaso com parcelas subdivididas em esquema fatorial $9 \times 3$, com oito inseticidas/doses (Tabela 1) e um controle, três tratamentos (adição de $\mathrm{NaCl}$, adjuvante Acquamax ${ }^{\circledR}$, e sem aditivo/adjuvante) e quatro repetições. Ao todo, foram testadas 27 cenários distintos, perfazendo 108 sub-parcelas. Os quatro blocos foram casualizados com os inseticidas, e as sub-parcelas casualizadas com os três tratamentos.

Os blocos possuíam $90 \mathrm{~m} \times 12 \mathrm{~m}$, e foram divididos em 9 parcelas de $10 \mathrm{~m} \times 12 \mathrm{~m}$, as parcelas 
foram divididas em 3 sub-parcelas de $10 \mathrm{mx} 4 \mathrm{~m}$, totalizando 108 sub-parcelas de $40 \mathrm{~m}^{2}$, ou $4030 \mathrm{~m}^{2}$. Para demarcação do experimento foram utilizadas 110 estacas de bambu de $1 \mathrm{~m}$, coletadas na propriedade. Utilizou-se fita zebrada para separar os blocos, a fim de auxiliar na pulverização.

Após a demarcação do ensaio foi realizada a amostragem prévia. Utilizou-se o pano de batida de cor branca com $1 \mathrm{~m}$ x $0.4 \mathrm{~m}$ para coletar as amostras. $\mathrm{O}$ mesmo era introduzido entre as duas linhas centrais de cada sub-parcela, e as plantas eram sacudidas vigorosamente para que os insetos caíssem sobre o pano. Em seguida, os insetos coletados eram identificados e quantificados. Foi colhida uma amostra por avaliação em cada sub-parcela.

\subsection{Calibragem do pulverizador}

A aplicação foi realizada por meio de pulverizador costal pressurizado com tanque de $\mathrm{CO}_{2}$ (Herbicat ${ }^{\circledR}$, Catanduva-SP), próprio para pesquisa. O pulverizador contém barra com seis bicos anti-gotejo, espaçados a 0,5 M, e pontas modelo 110-02 $\left(\right.$ MagnoJet $\left.{ }^{\circledR}\right)$, com faixa aplicada de 3 metros. Foram deixados 0,5 metros de cada lado da faixa aplicada para anular o efeito da deriva. O equipamento foi calibrado para o volume de calda de150 L/ha, com pressão de 0,75 Kgf de acordo com o manômetro da barra. A velocidade foi $4,5 \mathrm{~km} / \mathrm{h}$, e o tempo para percorrer a sub-parcela foi de 8 segundos, monitorados via cronômetro. As condições de aplicação foram com temperatura de 25 a 36 graus, umidade relativa 70\%, a aplicação foi feita de sub-parcela a sub-parcela.

\subsection{Preparo da calda e produtos aplicados}

Utilizou-se 36 garrafas PET para o preparo da calda, que foi de 1.81 por tratamento. Utilizou-se o micropipetador modelo Kasvi IC15081 100 - $1000 \mu \mathrm{l}$, e balança de precisão Gehaka modelo BK-6000, e todos os EPI (equipamento de proteção individual) necessários. A dosagem foi definida de acordo com a bula do produto.

Tabela 1: Tratamentos utilizados com suas características de produto comercial (PC), dose por ha-1 $\left(\mathrm{D}-\mathrm{g} / \mathrm{mL}^{-}\right.$ ha $^{-1}$ ) ingrediente ativo (I.A.) e grupo químico (G.Q.) aplicados no experimento da Fazenda Pai José, Vila Propício/GO, 2018.

\begin{tabular}{|c|c|c|c|}
\hline PC & $\mathrm{D}$ & I.A. & G.Q. \\
\hline $\begin{array}{l}\text { Hero }^{\circledR} \\
\text { Hero }^{\circledR}\end{array}$ & $\begin{array}{l}80 \mathrm{~mL} \\
100 \mathrm{~mL}\end{array}$ & $\begin{array}{l}\text { Cipermetrina }+ \\
\text { Bifentrina }\end{array}$ & Piretróide** \\
\hline Perito $970 \mathrm{SG}^{\circledR}$ & $700 \mathrm{~g}$ & Acefato & Organofosforado \\
\hline Perito $970 \mathrm{SG}^{\circledR}$ & $1000 \mathrm{~g}$ & & \\
\hline Connect $^{\circledR}$ & $500 \mathrm{~mL}$ & $\begin{array}{c}\text { Imidacloprido+ } \\
\text { Betaciflutrina }\end{array}$ & $\begin{array}{c}\text { Neonicotinoide+ } \\
\text { Piretróide }\end{array}$ \\
\hline Engeo Pleno ${ }^{\circledR}$ & $200 \mathrm{~mL}$ & $\begin{array}{c}\text { Tiametoxam }+ \\
\text { Lambdacialotrina }\end{array}$ & $\begin{array}{c}\text { Neonicotinoide+ } \\
\text { Piretróide }\end{array}$ \\
\hline Decis $25 \mathrm{EC}^{\circledR}$ & $300 \mathrm{~mL}$ & Deltametrina & Piretróide \\
\hline
\end{tabular}

* Os produtos Engeo Pleno ${ }^{\circledR}$ e Decis ${ }^{\circledR}$ não possuem doses máxima e mínima.

**Modo de ação: Piretróide (moduladores canais de sódio); Organofosforado (inibidores acetilcolinesterase) e Neonicotinoide (mod. competitivos de receptores nicotínicos da acetilcolina). 


\subsection{Amostragens e análises estatísticas}

Foram realizadas duas amostragens após a aplicação, com 24 e 72 horas após a pulverização.

Os dados foram submetidos à análise de variância utilizando o procedimento GLM (SAS Institute 2004). O procedimento SLICE (SAS Institute 2004) foi utilizado nas análises de efeitos simples para decompor as interações significativas, seguindo do teste de Tukey para separação das médias (NOGUEIRA; CORRENTE, 2000).

As transformações utilizadas foram $\sqrt{x+1}$ para as variáveis número de percevejos por metro antes, e com 24 e 72 horas após a aplicação.A eficiência de controle foi transformada utilizando o $\operatorname{arco-seno} \sqrt{\% / 100}+0,5$.

\section{RESULTADOS E DISCUSSÃO}

Não houve interação significativa pela análise de variância entre os fatores inseticidas/doses e adjuvantes/aditivos para nenhuma variável avaliada ao longo do experimento $(p>0,05)$. Assim, cada fator foi analisado separadamente.

Houve diferença significativa entre os inseticidas/doses para o número de percevejos maiores que $0,5 \mathrm{~cm}$ por metro com $24(\mathrm{p}<0,0001)$ e 72 horas $(p<0,001)$ após a aplicação dos inseticidas. Também houve diferença entre os inseticidas/dosespara a eficiência de controle dos percevejos com $24(\mathrm{p}<0,005)$ e 72 horas $(p<0,0005)$ após a aplicação dos inseticidas (Tabela 2).

Os produtos doses Hero ${ }^{\circledR} 100 \mathrm{~mL}$ ha-1 contato/ingestão

$$
\text { (Cipermetrina+Bifentrina) }
$$

e Decis ${ }^{\circledR} 300 \mathrm{ml} / \mathrm{ha}$ contato/ingestão (Deltametrina) apresentaram o maior número de percevejos grandes por metro quando comparados ao Connect ${ }^{\circledR} 1000$ $\mathrm{ml} / \mathrm{ha}$ sistêmico e contato/ingestão (Imidacloprido+Betaciflutrina) e Engeo Pleno ${ }^{\circledR} 200$ $\mathrm{ml} / \mathrm{ha}$ sistêmico e contato/ingestão (Tiametoxam+Lambdacialotrina) com 24 horas após a aplicação (Tabela 2). Na avaliação realizada 72 horas após a aplicação, o produto comercial Perito 970 $\mathrm{SG}^{\circledR} 1000 \mathrm{~g} /$ ha sistêmico e contato/ingestão (Acefato) apresentou o menor número de insetos por metro em comparaçãoao Hero $^{\circledR} \quad 80 \quad$ e $100 \quad \mathrm{ml} / \mathrm{ha}$ (Cipermetrina+Bifentrina) e Decis25 EC ${ }^{\circledR} 300 \mathrm{ml} / \mathrm{ha}$ (Deltametrina) (Tabela 2).

$$
\text { Apenas o } \text { Connect }^{\circledR} 1000 \quad \mathrm{ml} / \mathrm{ha}
$$

(Imidacloprido+Betaciflutrina) manteve os percevejos abaixo do nível de controle no primeiro dia após a aplicação (menos de dois percevejos por metro linear), mas isso não se repetiu no terceiro dia (Tabela 2). Provavelmente, isso se deve à densidade populacional extremamente elevada na área experimental e nas áreas adjacentes.

Aparentemente, o número de percevejos encontrados na amostragem prévia não influenciou o desempenho dos inseticidas com o melhor e pior desempenho (Tabela 2).

Também houve diferença estatística significativa entre os inseticidas/doses para a eficiência de controle com $24(p<0,005)$ e 72 horas $(p<0,0001)$ após a aplicação dos inseticidas (Tabela 2).

$$
\text { O Connect }{ }^{\circledR} 1000 \quad \mathrm{ml} / \mathrm{ha}
$$

(Imidacloprido+Betaciflutrina) foi o produto mais eficiente no controle dos percevejos em comparação ao Decis25 EC ${ }^{\circledR} 300 \mathrm{ml} / \mathrm{ha}$ (Deltametrina) e Hero ${ }^{\circledR} 80$ $\mathrm{ml} / \mathrm{ha}$ (Cipermetrina+Bifentrina) (Tabela 2). 


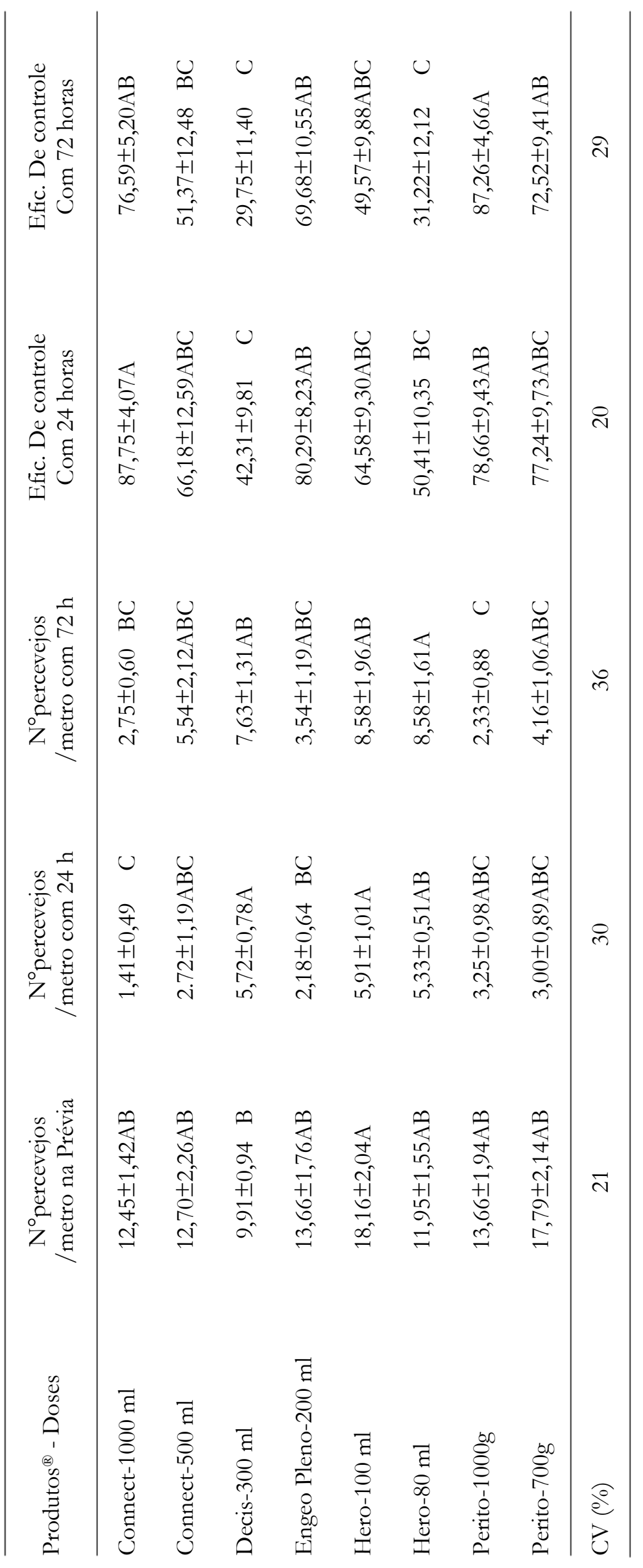


O Engeo Pleno ${ }^{\circledR} \quad 200 \quad \mathrm{ml} / \mathrm{ha}$ (Tiametoxam+Lambdacialotrina) e Perito 970 $\mathrm{SG}^{\circledR} 1000 \mathrm{~g} / \mathrm{ha}$ (Acefato) também foram mais eficientes na supressão de pentatomídeos do que o Decis25 EC ${ }^{\circledR} 300 \mathrm{ml} /$ ha (Deltametrina) com 24 horas após a aplicação (Tabela 2).

Após 72 horas da aplicação dos produtos, os inseticidasPerito 970 SG ${ }^{\circledR} 1000 \mathrm{~g} / \mathrm{ha}$ (Acefato), $\begin{array}{llll}\text { Engeo } & \text { Pleno }{ }^{\circledR} & 200 \quad \mathrm{ml} / \mathrm{ha}\end{array}$ (Tiametoxam+Lambdacialotrina) e Connect ${ }^{\circledR} 1000$ $\mathrm{ml} /$ ha (Imidacloprido+Betaciflutrina) tiveram melhor efeito residual dos que os Piretróides Decis25 EC ${ }^{\circledR 300}$ $\mathrm{ml} / \mathrm{ha}$ (Deltametrina) e Hero ${ }^{\circledR} 80$ ml/ha (Cipermetrina+Bifentrina). O Perito 970 SG ${ }^{\circledR} 1000$ $\mathrm{g} / \mathrm{ha}$ (Acefato) ainda foi mais eficiente no controle de percevejos do que o Connect $^{\circledR} 500 \quad \mathrm{ml} / \mathrm{ha}$ (Imidacloprido+Betaciflutrina) (Tabela 2).

Tanto o Hero ${ }^{\circledR}$ (Cipermetrina+Bifentrina) quando o Decis $25 \mathrm{EC}^{\circledR}$ (Deltametrina) pertencem ao grupo químico dos Piretróides, e promovem o fluxo excessivo de íons $\mathrm{Na}^{+}$para dentro da membrana axônica, matando o inseto por hiperexcitação do sistema nervoso (FOLDE IRAC, 2013). Esses produtos precisam entrar em contato com os insetos ou serem ingeridos, desse modo, são mais indicados para insetos mastigadores do que para insetos sugadores (GALLO et al., 2002). Ambos tem registro para Euschistos eros (percevejo marrom) na cultura da soja, mas não são capazes de matar os percevejos que encontram-se no terço médio e inferior da cultura, escondidos sobre as folhas e vagens.

Os inseticidas sistêmicos são mais indicados para insetos como os percevejos da soja (Hemiptera: Pentatomidae), e para outros insetos sugadores que habitam locais onde o inseticida de contato e ingestão não chega. Esses inseticidas são absorvidos pelas plantas e entram em contato com os insetos por meio da seiva ingerida (GALLO et al., 2002). Essa é uma das razões pelas quais o desempenho dos inseticidas Perito 970 SG $^{\circledR}$ (Acefato), Connect ${ }^{\circledR}$ (Imidacloprido+Betaciflutrina), e Engeo Pleno ${ }^{\circledR}$ (Tiametoxan+Lambdacialotrina) foram mais eficientes, todos tem pelo menos um ingrediente ativo com ação sistêmica (Organofosforados ou Neonicotinóides).

Sabe-se que os Piretróides possuem limitações quando à absorção pelas plantas, uma vez que agem por contato e ingestão. Dessa forma, a maioria dos trabalhos que estuda a eficiência de moléculas voltadas para o controle de percevejos não avalia os Piretróides separadamente (FIORIN et al., 2011; RIBEIRO et al., 2016; GOELZER et al., 2017). Apenas o Connect ${ }^{\circledR}$, Engeo Pleno ${ }^{\circledR}$ e Perito970 SG ${ }^{\circledR}$ apresentaram eficiência de controle superior a 80\% com 24 horas após a aplicação. $\mathrm{Na}$ avaliação com 72 horas após a aplicação, apenas o Perito ${ }^{\circledR}$ na dose máxima apresentou eficiência de controle superior a 80\%. Essa eficiência de controle é a mínima esperada para inseticidas com registro no MAPA (GOELZER et al., 2017).

Não há um consenso da Literatura sobre qual ou quais moléculas são melhores no controle de percevejos em soja. De modo geral, a maioria dos trabalhos afirma que a mistura entre Neonicotinóides e Piretróides é mais eficiente no controle de percevejos (RIBEIRO et al., 2016; GOELZER et al., 2017).

Não foram encontradas diferenças expressivas entre Neonicotinoites+Piretróides com Organofosforados, assim como Fiorin et al. (2011) observaram.

Existem relatos de casos de resistência do percevejo marrom ao ingrediente ativo Acefato (FOLDER IRAC, 2016). Curiosamente, o inseticida que apresentou a maior eficiência de controle com 72 horas após a aplicação foi $\mathrm{O}$ Perito ${ }^{\circledR}$ (Acefato/Organofosforado), na dose de $1 \mathrm{~kg} / \mathrm{ha}$. Assim, infere-se que pode haver populações de percevejos mais suscetíveis ao Acefato na região de Goianésia-GO. Outra possível explicação consiste na 
concentração de Ingrediente Ativo (IA) do produto comercial. O Perito ${ }^{\circledR}$ possui 970 gramas de I.A. por quilo, e essa concentração é maior do que $90 \%$ dos produtos comerciais a base de Acefato registrados no Brasil. Apenas o Evolution ${ }^{\circledR}$ possui a mesma concentração de ingrediente ativo, mas não possui registro para a cultura da soja (AGROFIT, 2018).

É possível que a baixa eficiência de controle de alguns produtos esteja relacionada à senescência. A área já estava com mais de 90 dias após a semeadura, e as folhas da soja começaram a cair de forma muito intensa no quarto dia após a aplicação. Quase não havia folhas nas plantas aos sete dias após a instalação do ensaio. É possível que isso tenha prejudicado a absorção dos produtos, uma vez que as folhas já se encontravam no início do processo de senescência durante a montagem do ensaio.

Uma das principais bases do Manejo Integrado de Pragas (MIP) são os níveis populacionais, que consideram a densidade da praga por área, planta, fruto, etc. O Nível de Controle (NC) foi estabelecido para que a praga possa ser controlada antes de causar prejuízos ao produtor. A partir do momento que a densidade populacional dos insetos ultrapassa o Nível de Dano econômico, ocorrem perdas de ordem financeira, e o controle fica mais difícil (STERN, 1959).

Densidades populacionais elevadas após a aplicação evidenciam que a população da praga estava muito acima do NC, especialmente se a eficiência de controle foi superior a $80 \%$. Por mais eficiente que seja o produto, é difícil reduzir populações que estão 5 a 8 vezes maior do que o NC, e isso foi observado nesse trabalho.

Uma das quatro bases do MIP é a mortalidade natural do sistema, para tanto, a sobrevivência dos inimigos naturais (predadores e parasitóides) é fundamental para evitar surtos populacionais e ressurgência de pragas (GALLO ET al., 2002).
Mais de 95\% dos inseticidas registrados para percevejos na cultura soja não são seletivos, pois utilizam ingredientes ativos que pertencem ao grupo químico dos Organofosforados e Piretróides (KOOPERT DO BRASIL, 2018). Essa estratégia adotada pelas empresas fabricantes dificulta ainda mais o controle dos percevejos, pois elimina insetos benéficos que poderiam auxiliar na redução da densidade populacional de percevejos e outros insetospraga (GALLO ET al., 2002).

Não houve diferença significativa pela análise de variância entre os adjuvantes/aditivos para o número de percevejos por metro com 24 e 72 horas após a aplicação $(p>0,05)$. Entretanto, a eficiência de controle dos percevejos foi diferente entre os adjuvantes/aditivos com $24(\mathrm{p}<0,0005)$ e 72 horas $(\mathrm{p}<0,05)$ após a instalação do ensaio (Tabela 3).

O sal $0,5 \%$ de cozinha maximizou o controle de percevejos em comparação ao Acquamax ${ }^{\circledR}$ $250 \mathrm{ml} /$ há e à ausência de aditivos na primeira avaliação após a instalação do ensaio. Já na segunda avaliação (72 h), o Acquamax $^{\circledR}$ teve um desempenho inferior às parcelas em que não se utilizou nenhum aditivo (Tabela 3).

O sal de cozinha $\mathrm{NaCl}$ é utilizado com a finalidade de aumentar o tempo de permanência dos percevejos na planta tratada, além de possibilitar a redução da dose do inseticida (CORSO, 1998). O aumento do tempo de permanência dos insetos na planta pode maximizar a absorção do ingrediente ativo, além de aumentar probabilidade de o inseto entrar em contato com o produto. 


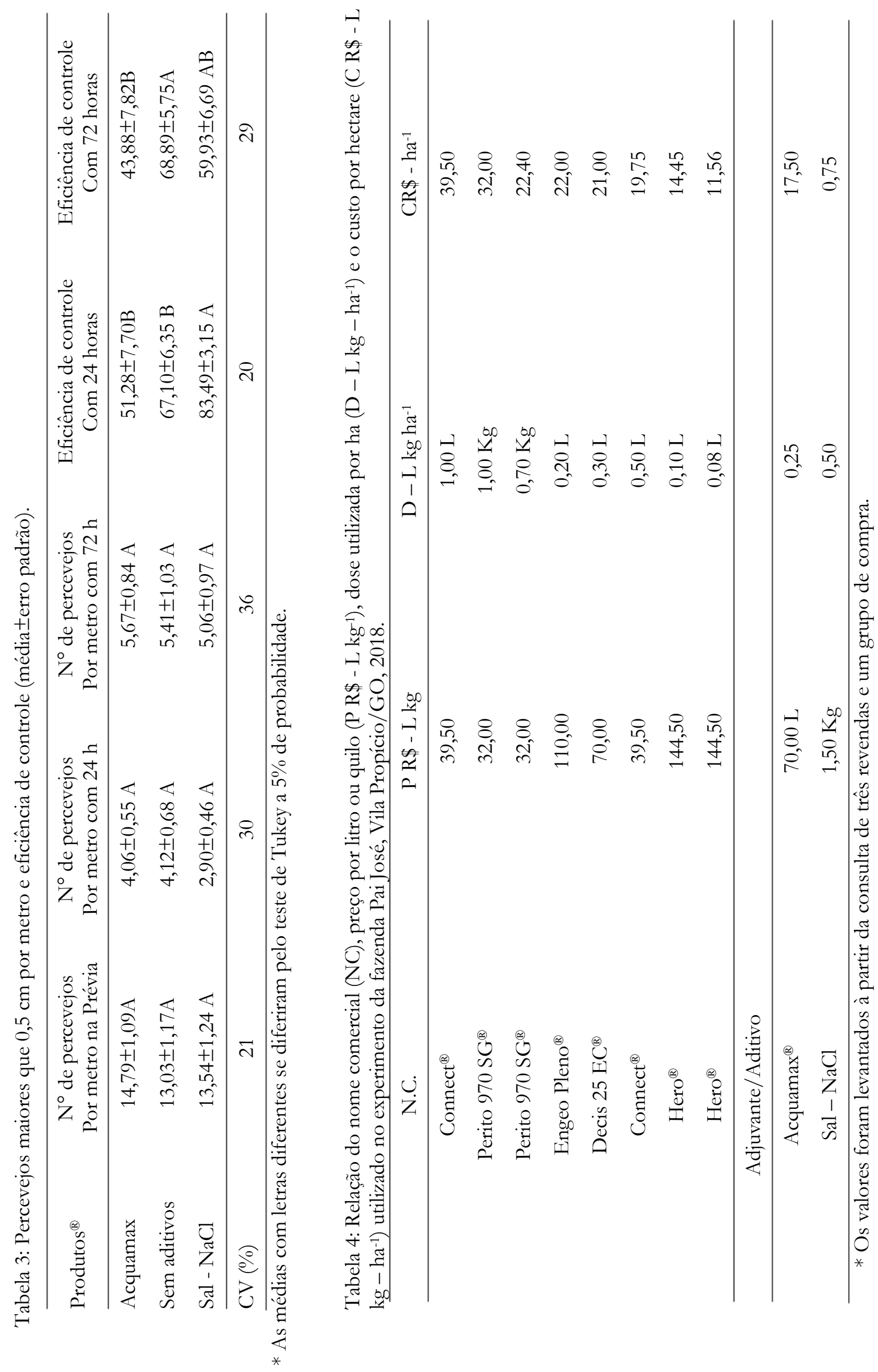


O Acquamax ${ }^{\circledR}$ é um adubo foliar vendido como redutor de ph e adjuvante agrícola, e tem o ácido ortofosfórico como principal ingredientes ativos. O problema é que na menor dose recomendada pelo fabricante, o produto baixa o ph das águas da região para níveis inferiores a 3 (PEIXOTO, 2016).A maioria dos estudos presentes na literatura recomendam que $\mathrm{o}$ $\mathrm{pH}$ da água deve ser mantido entre 6 e 6,5 (KISSMANN, 1998;AZEVEDO,2011).O Glifosato é um dos poucos exemplos de produtos que são eficientes em caldas com $\mathrm{pH}$ próximo de 3,5 (KISSMANN, 1998).A redução excessiva do $\mathrm{pH}$ da calda pode reduzir a eficiência dos ingredientes ativos (SILVA \& MOSCARDI, 2002; HIRATA ET al., 2003; OLIVEIRA ET al., 2005;SANCHOTENE ET al., 2007; AZEVEDO, 2011).

Os dois produtos mais eficientes (Perito ${ }^{\circledR}$

e Connect $\left.{ }^{\mathbb{R}}\right)$ também são aqueles que apresentam o maior custo por hectare. De acordo com os dados obtidos no trabalho é possível inferir que há uma tendência de que quanto maior o custo por hectare tratado, maior é a eficiência de controle do produto (Tabela 4).

Caso o produtor opte pela máxima eficiência de controle, a melhor escolha é o Perito ${ }^{\circledR}$ (Acefato) e Connect ${ }^{\circledR}$ (Imidacloprido+Betaciflutrina) na dose de $1 \mathrm{Kg} \mathrm{L} \mathrm{ha}^{-1}$. Já o Engeo Pleno ${ }^{\circledR}$ (Tiametoxan+Lambdacialotrina) e o Perito ${ }^{\circledR}$ (Acefato) na menor dose possuem a mesma eficiência dos demais do ponto de vista estatístico, com um custo 44-30\% menor (Tabela 4).

O custo por hectare tratado do Acquamax ${ }^{\circledR}$ é superior ao de alguns produtos testados (Tabela 4). O custo elevado do Acquamax ${ }^{\circledR}$ associado à interferência negativa na redução do residual dos inseticidas testados inviabiliza sua adoção. A relação de custo-benefício da adição do sal de cozinha se mostrou extremamente vantajosa, uma vez que o custo por hectare é de apenas $R \$ 0,75$, e o aumento na eficiência de controle é superior a $15 \%$.

\section{CONCLUSÕES}

$$
\text { O } \quad \text { Connect }^{\circledR} \quad 11 / \text { há }
$$

(Imidacloprido+Betaciflutrina)reduziu a população de 12,4 pata 1,4 percevejospor metro com 24 horas após a aplicação.

Perito ${ }^{\circledR} 1 \mathrm{~kg} / \mathrm{ha}$ (Acefato) foi o produto com residual mais alto, apresentando mais de $80 \%$ de eficiência de controle com 72 horas após a instalação do ensaio.

Nenhum inseticida manteve a população de percevejos abaixo do Nível de Controle no terceiro dia após a aplicação.

Os Neonicotinoides+Piretóides e Organosfosforados foram mais eficientes no controle de percevejos do que os Piretróides.

Não há justificativa econômica ou agronômica para a utilização do adjuvanteAcquamax ${ }^{\circledR}$ na aplicação de inseticidas.

Engeo $\quad$ Pleno $^{\circledR}$ (Tiametoxan+Lambdacialotrina) e o Perito ${ }^{\circledR}$ (Acefato) na menor dose possuem alta eficiência de controlee custo $44-30 \%$ menor.

A relação de custo-benefício da adição do sal de cozinha se mostrou extremamente vantajosa, com custo de $R \$ 0,75 /$ ha e aumento na eficiência de controle superior a $15 \%$.

\section{REFERÊNCIAS BIBLIOGRÁFICAS}

AZEVEDO, L.A.S. Adjuvantes agrícolas para a proteção de plantas. Seropédica: IMOS, p. 264, 2011.

BATISTELA, M. J. Níveis de desfolha e táticas de manejo de pragas na cultura da soja. 2010. Tese (Pós-graduação em produção vegetal) Universidade de Rio Verde, FESURV, Rio Verde 2010. 
BRIDI, M. Danos de percevejos pentatomídeos(Heteroterma Pentatomidae) nas culturas da soja e do milho na região centro-sul do Paraná. 2012. 73 f. Tese (programa de pós graduação em agronomia) -Universidade estadual do centro oeste Unicentro, Guarapuava, 2012.

BUENO, A. de F.; BORTOLOT'TO, O.C.; POMARI, A.F.; ROGGIA, S.;

BUENO, A. F.; SOSA-GÓMEZ, D. R.; CORRÊAFERREIRA, B. S; MOSCARDI, F.; BUENO, R. C. O. F. Inimigos naturais das pragas da soja. In: HOFFMANN-CAMPO, C. B., CORREAFERREIRA， B. S., MOSCARDI, F. Soja: manejo integrado de insetos e outros artrópodespraga. Embrapa, 2012, p. 491-629.

BUENO, F.A., BATISTA, M. J.; MOSCARDI. F.; BUENO, R.C.O.F.; NISHIKAWA. M.; HIDALGO. G.; SILVA. L.; GARCIA. A.; CORBO. E.; SILVA. R. B. Controle de pragas apenas com o MIP. Embrapa soja. P. 78, 2010.

COMITÊ BRASILEIRO DE AÇÃO A RESISTÊNCIA A INSETICIDAS (IRAC BR). Classificação do modo de ação de inseticidas: a chave para o manejo da resistência a inseticidas. Mogi Mirim, SP, 2 p. 2016.

\section{COMPANHIA NACIONAL DE ABASTECIMENTO (CONAB). \\ Acompanhamento da safra Brasileira de grãos. v. 5, n. 5, 142 p. fevereiro, 2018.}

CONTE, O.; OLIVEIRA, T. F.; HANGER, N.; CORREAA-FERREIRA, S. B.; ROGGIA, S. Resultado do manejo integrado de pragas da soja na safra 2014/15 no Paraná. Embrapa soja. 60 p. Londrina-PR, 2015

CORRÊA-FERREIRA, B.S.; FRANÇA-NETO, J.B. Quando se deve controlar percevejos na soja. Londrina-PR. Agosto, 2003.

CORSO, I. C.; GAZZONI, L. D. Sodium chloride: An insecticide enhancer for controlling pentatomids on soybeans. Pesq. agropecuária. Brasileira, Brasília-DF, v.33, n 10, p.1563-1571, out. 1998

\section{EMPRESA BRASILEIRA DE PESQUISA AGROPECUÁRIA (EMBRAPA SOJA).Controle de pragas apenas com o MIP. Janeiro, 2010. 78 p.}

EMPRESA BRASILEIRA DE PESQUISA AGROPECUÁRIA (EMBRAPA). Manejo da resistência do Percevejo-marrom a inseticidas. Folder: 10.00 exemplares junho/2013. CGPE 10.251, junho/2013.

FIORIN, R. A.; STURNER, G. R.; GUEDES, J. V. C.; COSTA, I. F. D.; PERINI, C. R. Métodos de aplicação e inseticidas no controle de percevejos na cultura da soja. Semina: Ciências Agrárias, Londrina, v. 32, n. 1, p. 139-146, jan/mar. 2011.

FREITAS, M. C. M. A Cultura da soja no Brasil: O Crescimento da produção brasileira e o surgimento de uma nova fronteira agrícola. 2011. 12 f. Tese (Pós-graduando em Agronomia) Universidade Federal de Uberlândia, Uberlândia, 2011.

GALLO, D.; O. NAKANO; S.; SILVEIRA NETO; R. P. L.; CARVALH, G. C.; BAPTISTA, E.; BERTI FILHO, J. R. P.; PARRA; R. A. ZUCCHI, S. B.; ALVES, J. D.; VENDRAMIM, L. C.; MARCHINI, J. R. S.; LOPES \& C. OMOTO. 2002.Manual de Entomologia Agrícola: toxicologia de inseticidas. Piracicaba, SP: FEALQ, 920p.

GALLO, D.; O. NAKANO; S.; SILVEIRA NETO; R. P. L.; CARVALH, G. C.; BAPTISTA, E.; BERTI FILHO, J. R. P.; PARRA; R. A. ZUCCHI, S. B.; ALVES, J. D.; VENDRAMIM, L. C.; MARCHINI, J. R. S.; LOPES \& C. OMOTO. 2002. Manual de Entomologia Agrícola: Métodos de controle de pragas. Piracicaba, SP: FEALQ, 920p

GOELZER, G.; NUNES, J.; MOSCARDINI, V. F.; GONTIJO, P. C. Eficiência de inseticidas no controle de Euschistus heros na cultura da soja no estado do Paraná. Cultivando o saber, edição especial. P.117-124, 2017.

HIRATA, R.; SKORTZARU, B.; NARCISO, E.S. Avaliação da degradação de inseticidas, em função do ph, utilizando Drosophila melanogaster e teste de inibição enzimática. Arquivo do Instituto Biológico, v. 70, n. 3, p. 359-365, 2003.

HUSCH, P. E. Suscetibilidade a inseticidas, atividade enzimática e variabilidade genética em Euchistus heros (f., 1798) (HEMIPTERA: PENTATOMIDAE). 2016. 82 f. Tese (Pósgraduação em Ciências Biológicas, Área e concentração em Entomologia) -Universidade Federal do Paraná. Curitiba, 2016. 
KISSMANN, K.G. Adjuvantes para caldas de produtos fitossanitários. In: GUEDES, J.V.C \& DORNELLES, S.B (Org.) Tecnologia e segurança na aplicação de agrotóxicos: novas tecnologias. Santa Maria: Departamento de Defesa Fitossanitária; Sociedade de Agronomia de Santa Maria, p. 39-51, 1998.

MAZIERO, H. Estudos de tecnologias de aplicação e inseticidas para o controle de percevejos fitófagos na cultura da soja. 2006. Tese (mestrado em agronomia) -Universidade Federal de Santa Maria, Centro de ciências rurais Programa de pós-graduação em agronomia, Santa Maria, Rio Grande do Sul, 2006.

OLIVEIRA, M.F.; PRATES, H.T.; SANS, L.M.A. Sorção e hidrólise do herbicida flazasulfuron. Planta Daninha, v. 23, n. 1, p. 101-113, 2005.

PEIXOTO, R.L.O. Adequação do pH de águas utilizadas na aplicação de defensivos na região de Goianésia - GO. Orientação de Daniel Ferreira Caixeta - Goianésia, 2016. 28p.Tese (Monografia de Graduação) - Faculdade Evangélica de Goianésia, 2016.

RIBEIRO, F. C.; ROCHA, F. S.; ERASMO, E. A. L.; MATOS, E. P.; COSTA, S. J. Manejo com inseticidas visando o controle de percevejo marrom na soja intacta. Revista de Agricultura
Neotropical, Cassilândia-MS, v. 3, n. 2, p. 48-53, abr./jun. 2016.

SANCHOTENE, D. M.; DORNELLES, S.H.B.; DEBORTOLI, M.P.; CAPITANIO, J.R.; MEZZOMO, R.F.; GONÇALVES, R.A. Influência de sais e do pH da água na eficiência de imazethapyr+ imazapic no controle de arrozvermelho. Planta Daninha, v. 25, n. 2, p. 415-419, 2007.

SAS INSTITUTE. SAS/STAT user'sguide, release 9.1 ed. SAS Institute, Cary, NC, 2004

SILVA, M.T.B.; MOSCARDI, F. Field efficacy of the nucleopolyhedrovirus of Anticarsia gemmatalis Hübner (Lepidoptera: Noctuidae): effect of formulations, water $\mathrm{pH}$, volume and time ofapplication, andtypeof spray nozzle. Neotropical Entomology, v. 31, n. 1, p. 75-83, 2002.

SOSA-GÓMEZ, D.R. Medidas para prevenir o aparecimento de resistência emPopulações de percevejos. Londrina: Embrapa Soja, 2010. 1 folder.

VERNON, M.; STERN, R.; SMITH, R. VAN DEN. B.; AND, K. S.; HAGEN. University of California-Berkeley, v. 29, n. 2, 23 p. 1959. 